University of Wollongong

Research Online

Faculty of Engineering and Information

Faculty of Engineering and Information

Sciences - Papers: Part A

Sciences

$1-1-2015$

Drawing micro learning into MOOC: using fragmented pieces of time to enable effective entire course learning experiences

Geng Sun

University of Wollongong, gs147@uowmail.edu.au

Tingru Cui

University of Wollongong, tingru@uow.edu.au

Jianming Yong

University of Southern Queensland

Jun Shen

University of Wollongong, jshen@uow.edu.au

Shiping Chen

CSIRO ICT Centre, shiping.chen@csiro.au

Follow this and additional works at: https://ro.uow.edu.au/eispapers

Part of the Engineering Commons, and the Science and Technology Studies Commons

Research Online is the open access institutional repository for the University of Wollongong. For further information contact the UOW Library: research-pubs@uow.edu.au 


\title{
Drawing micro learning into MOOC: using fragmented pieces of time to enable effective entire course learning experiences
}

\author{
Abstract \\ Recently the massive open online course (MOOC) is an emerging trend that attracts many educators' and \\ researchers' attentions. Based on our pilot study focusing on the development and operation of MOOC in \\ Australia, we found $\mathrm{MOOC}$ is featured with mastery learning and blended learning, but it suffers from low \\ completion rates. Brining micro learning into MOOC can be a feasible solution to improve current MOOC \\ delivery and learning experience. We design a system which aims to provide adaptive micro learning \\ contents as well as learning path identifications customized for each individual learner. To investigate \\ how micro learning can impact learning experience and knowledge acquisitions of learners participated in \\ $\mathrm{MOOC}$, we suggest a potential scheme including hypotheses to evaluate our proposed approach.

\section{Keywords} \\ course, entire, effective, enable, time, pieces, fragmented, experiences, mooc, drawing, into, learning, \\ micro \\ Disciplines \\ Engineering | Science and Technology Studies

\section{Publication Details} \\ Sun, G., Cui, T., Yong, J., Shen, J. \& Chen, S. (2015). Drawing micro learning into MOOC: using fragmented \\ pieces of time to enable effective entire course learning experiences. International Conference on \\ Computer Supported Cooperative Work in Design (pp. 308-313). IEEE CPS.
}




\section{Drawing Micro Learning into MOOC: Using Fragmented Pieces of Time to Enable Effective Entire Course Learning Experiences}

\author{
Geng Sun, Tingru Cui \\ School of Information Systems and Technology \\ University of Wollongong \\ Wollongong, Australia \\ gs147@uowmail.edu.au, tingru@uow.edu.au \\ Jun Shen \\ School of Information Systems and Technology \\ University of Wollongong \\ Wollongong, Australia \\ jshen@uow.edu.au
}

\author{
Jianming Yong \\ School of Management and Enterprise \\ University of Southern Queensland \\ Toowoomba, Australia \\ Jianming.Yong@usq.edu.au
}

\author{
Shiping Chen \\ ICT Centre \\ CSIRO \\ Sydney, Australia \\ shiping.chen@csiro.au
}

\begin{abstract}
Recently the massive open online course (MOOC) is an emerging trend that attracts many educators' and researchers' attentions. Based on our pilot study focusing on the development and operation of MOOC in Australia, we found MOOC is featured with mastery learning and blended learning, but it suffers from low completion rates. Brining micro learning into MOOC can be a feasible solution to improve current MOOC delivery and learning experience. We design a system which aims to provide adaptive micro learning contents as well as learning path identifications customized for each individual learner. To investigate how micro learning can impact learning experience and knowledge acquisitions of learners participated in MOOC, we suggest a potential scheme including hypotheses to evaluate our proposed approach.
\end{abstract}

Keywords-MOOC, Mastery Learning, Blended Learning, Micro Learning, Resource Adaptation

\section{INTRODUCTION}

Nowadays learners have numerous choices to use various sorts of device, whenever they want and wherever they are, to get access to learning resources. The quantity of available learning resources is also exponentially rocketing. One of the most noticeable trends in that enrichment is, along with many leading universities open up access to their courses, the massive open online course (MOOC) gains its popularity in the whole higher education sector [1]. It is an online course targeting on large-scale interactive participation and open access via the Web, which is an important supplement to the traditional distance education [2]. Using MOOC, anyone from anywhere is given the equal opportunity to take courses and have access to educational content that they otherwise could not afford. The pioneer MOOC providers include Coursera (www.coursera.org), edX (www.edx.org), and Udacity (www.udacity.com). Australia also holds its own MOOC platform named OpenLearning (www.openlearning.com), initiated by University of New South Wales. Thereafter, several universities, including UOW and Monash University and a few others, join this group to share their educational contents over the internet. Till 2014, statistics show that millions of people are participating in the virtual classroom of MOOC, particularly, the number of students who are enrolled in a single course at the same time could be as high as tens of thousands [3]. The explosive growth of learning resources leads to a revolution of education and learning, and the year of 2012 was named as 'the year of MOOC' [4]. Educational professionals have strived extraordinarily on exploring the MOOC format as a regular pedagogical approach for $\mathrm{m}$ learning [5]. Many universities who contribute courses to MOOC providers gradually accredit the credits gained from MOOC learning. Learners who have accomplished a series of major-related MOOC courses can fulfill the requirements of a degree from those universities.

However, as research and development of MOOC are still in its infancy, there are evidently many opportunities to improve MOOC courses as well as their affiliations, such as learning platforms and learning support services, to enable easier access and better experience for both providers and customers

In this paper we will introduce the design of a novel system targeting on supporting smart micro learning in MOOC. In our pilot study, we investigated the development trend and acceptance of MOOC, particularly in Australia, and analyzed existing shortcomings as well as its potential improvement direction. Inspired from this, we attempt to use a system which aims to give learners opportunities to make the best use of every fragmented piece of time so as to effectively engage in the MOOC learning. In addition, we particularly concentrate on delivering learners adaptive learning resources in small chunks which are supposed to be learnt in relatively short duration, and sequencing these courses chunks in series as 
identified learning path. This new approach can be used either for learners who wish to complete an entire course to get credit, or those who just acquire the specific knowledge they actually need.

Section II will briefly introduce the principle of MOOC and what we have found out from our pilot study. Section III will give the definition of micro learning and discuss current challenges for bringing micro learning into MOOC. Based on it, we illustrate the framework of our system in Section IV. Section V will discuss proposed evaluation approach while finally Section VI will conclude this paper.

\section{BACKGROUND AND PRELIMINARY WORK}

\section{A. Background}

Online teaching through Massive Open Online Courses (MOOC) is one of the latest technologies in the field of education. MOOC, as an emerging technology, is evolving into new pedagogy to benefit teachers and students. It is offered for free and students of any age group could participate in the program. It works on an open network learning model. It enables participants to connect outside the traditional learning environment, thereby offering autonomy, openness and emergent knowledge. The growing trend of encouraging connected learning among students reflects the need for teachers to participate in an online course. Connected learning indicates that learning happens outside classrooms and through online networks and exchanges [6]. According to him, learning can take place informally by taking part in webinars, attending workshops, listening to Podcasts. This shows very clearly that a 21 st century educator has to be well connected, in order to prepare students for their career. It's a fact that educator's participation in MOOC would help them to encourage their students to effectively use their digital literacy for learning.

One key concern of MOOCs is it is currently suffering from low completion rate, with several sources indicating that about $5 \%$ to $15 \%$ of participants finish the courses on average while most learners who enrolled in MOOC courses ended up dropping out [7]. However, some authors suggest that dropout statistics might not be representing the only reality of MOOC learners. This is because different patterns of student behavior exist, and analyzing further each participant's objectives can provide additional insight into the different personal goals when attending a course besides finalizing it. Therefore

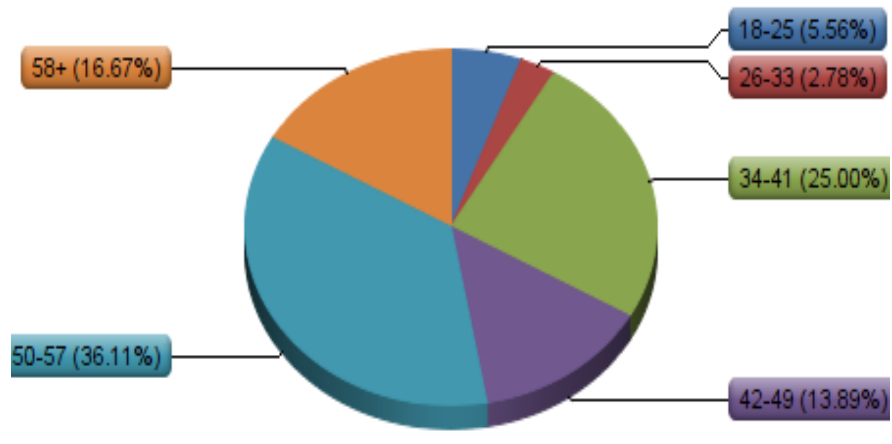

Figure 1. Age Group of Respondents different measures should be available in order to evaluate whether MOOCs are effective for individual participants[8]. Arguably, this is mainly because learners fail to conduct effective time management. Another crucial factor is believed that learners deem it is not easy to find appropriate resources they want, or the chosen resources do not match their expectation.

\section{B. Motivation and Preliminary Work}

MOOCs offer particular challenges for what is becoming accepted as mainstream practice in learning analytics. Because of the relative newness of MOOCs as a widespread phenomenon, there is not yet a substantial body of literature on the learning analytics of MOOCs. Data analysis is currently very limited, as existing MOOC platforms offer limited data storage and analysis, whereas usability to analyze this data is low [8]. To identify the features of MOOC that may influence the Australian educators and to develop a better understanding of how a higher education institutions and MOOC providers can inspire educators in order to increase their performance, we have conducted a survey to collect views regarding MOOC development and utilization from educators and practitioners in leading Australia education institutions. The Age groups and years of using MOOC of respondents can be referred to Figure 1 and 2, respectively. We are mainly interested in what benefits and important aspects of using MOOCs for Australian educators are, and how to encourage the Australian educators to use MOOCs. Using typical statistic methods to analyze their feedbacks, the main findings can be summarized as follows:

- Educator's intention is to continue using MOOCs.

- $\mathrm{MOOCs}$ have high importance regarding facilitate the presentation of online learning.

- MOOCs have low importance regarding provide instructors to learners.

- $\mathrm{MOOCs}$ have low importance regarding facilitate the instructions between collages.

- MOOCs have high importance regarding reuse of materials.

- MOOCs have low importance regarding automatic integration of results.

- $\quad$ MOOCs have low importance regarding free learning

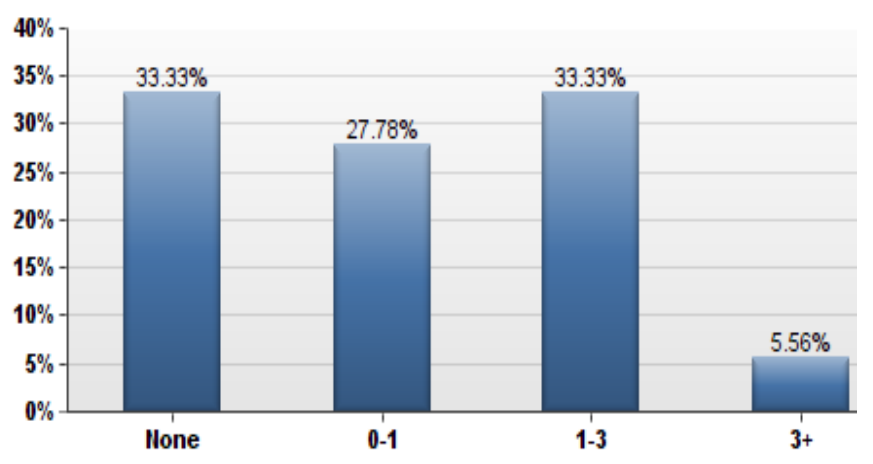

Figure 2. Years of Using MOOC 
ption.

- MOOCs have high importance regarding Mastery Learning

- MOOCs have high importance regarding Blended Learning

- It is very important that within MOOCs educators do not providing enough support to students.

- It is not very important for educators that MOOCs do not let them to have face to face interaction with students.

- It is not very important for educators that within MOOCs they cannot use perfect course design.

Among these findings, a noticeable future of MOOC is mastery learning. In mastery learning, students demonstrate the understanding of a concept through repeated assessment and exposure to material before moving on to the next lesson [9]. In many traditional classes, if a student attempts a homework assignment and does not do well, he or she simply gets a low score on the assignment and instruction moves to the next topic, providing the student a poor basis for learning the next concept. The feedback is also often given weeks after the concept was taught, by which point the student barely remembers the material and rarely goes back to review the concepts to understand them better. However, In the MOOC, the technology makes it easy to give immediate feedback on concepts the student did not understand. In many cases, Australian educators can provide randomized versions of the same assignment, so that a student can restudy and reattempt the homework. According to [9], the instructor's tools are designed to facilitate the use of question banks with extensive randomization. This strategy is aligned with general aim to leverage technology to support effective pedagogical approaches.

Another important factor for educators is the ability of blended learning. Blended learning (the strategic combination of face-to-face and online learning experiences) is growing in popularity within higher education and is a new educational model with great potential to increase student outcomes and create exciting new roles for teachers [10]. The Centre for the Support and Advancement of Learning and Teaching in Australia helps academic staff implement blended learning strategies into their courses and programs to enhance the students 'experience and the quality of learning and teaching. With this new technology, teachers no longer have to begin from scratch if they have a desire to teach using a blended learning model. With the recent explosion of digital educational resources, there are a number of great ones such as examine free resources, research the use of a learning management system and be prepared for potential setbacks in the road on the blended learning path [10]. These ways can help a teacher dive right into blending learning.

According to available studies to investigate MOOC's learner behavior tracks, it is found that MOOC follows the principles of micro learning - A MOOC is typically designed around the principles of micro learning enabling learners to go through bytes of learning in short duration. The modules ideally do not exceed 15 minutes. These small learning bytes not only aid quick assimilation but also makes it possible to learn on the go, thus reducing the dependency on a fixed time slot or the need to take a large chunk of time out of one's working day.

\section{PROBLEM ANALYSIS}

\section{A. Micro Learning in $\mathrm{MOOC}$}

Micro learning is claimed to have positive effects on mastery learning and be an important part of blended learning [11][12]. It can help learner make use of every fragmented piece of time to participate in learning activities in very short terms. Compared to accomplishing a course chunk with one or more interruptions, this can lead to positive effects for them to acquire targeted knowledge [13]. Learning in small steps (contrary to the traditional approach of learning through hourlong courses) is made possible with the aid of small and wellplanned chunks of units or activities. Thus micro learning becomes short-term, digestible, and easily manageable [14]. Micro learning also adapts to the constraints of the human brain with respect to its attention span. It is also supposed to align with research that proves people learn better when engaged in short, focused sessions, than hour-long sessions that cause information overload [15].

In literature, "micro learning" processes cover a time span from few seconds (e.g. in mobile learning) to up to 15 minutes or more. Another explanation of micro learning is deemed web focused: 'micro learning refers to short-term learning activities on small learning units. In the contemporary mobile/web society, micro learning pertains to small pieces of knowledge based on web resources' [14]. Compared to the traditional hour-long e-learning, micro learning features higher flexibility, and it can be in various forms, and, more importantly, it has less time limitation. In other words, it can be started anytime, whereas it may also be terminated anytime.

In mobile learning, learning activities occur for learners' conveniences, regardless the location and time. By this means, learners can get access to learning resources within various scenarios. With mobile devices, quite often learners accomplish learning missions in a short time period. According to the study conducted by [16], micro learning can be an assumption about the time needed to complete a relevant learning task, for example answering a question, memorizing an information item, or finding learning materials. Hence, micro learning booms with the wide use of mobile devices, and it becomes a major learning means in mobile environment. Micro learning shares some similar specialties with mobile learning as they are both individually referable, self-contained, reusable and re-mixable [17][18].

Australian educators use different kinds of multimedia to make the courses more comprehensive, help learners understand more effectively. The contents of courses can be reused among different courses. On the other hand, these popularly used course materials are in the form of visual information, while educational micro content is suggested to be in the similar form, which may consist of a text, a video, an audio, a picture, a graph, a drawing, a photo, etc. [19]. As 
micro learning evolves, micro-content delivery with a sequence of micro interactions enables users to learn without information overload [20]. It is a key technology to ensure better learning results in terms of retention of propositional content [15].

\section{B. Challenges}

MOOC practitioners have already made much effort to enable MOOC courses resources being workable in micro learning circumstances. For instance, some course materials have been chunked and sequenced from the simple to complex in order to enable faster processing by students. One popular way to link two micro course units is to add a simple assessment, normally in the form of quiz, true/false questions or multiple choices, between them. However, so far these trials have not been extended in large-scale MOOC deliveries.

Fragmented learning with mobile devices requires learners' concentration and reflection. However, being on the go (riding a train, sitting in a cafe, walking down the street) is fraught with distractions. Students are often found themselves in situations with unpredictable but significant annoyances on their attention. This leaves the mobile learners with a highly distracted, and at the same time, highly fragmented learning experience.

MOOC appeared along with the big data era. Statistics show that the number of online courses reach tens of thousands while the course modules affiliated to them rocket to millions. As a consequence, the operation of MOOC generates a huge amount of data about the learners, courses, educational institutions, networking, and technical details and so on. It could be very difficult for learners to quickly choose the preferred and suitable course chunks in a timely manner. Since the acquirable learning resources become massive, how to set and select the right and appropriate objectives, which stand out from the numerous available resources, brings a challenge for both MOOC providers and customers.

In addition, there are studies indicating that personality and learning styles play significant roles in influencing academic achievement [21]. As learners commonly do not have sufficient expertise in customizing learning schedule for themselves, and perhaps they are not familiar with their own learning styles, there are high probability that they cannot access to the right sets of micro content. This can affect them to achieve satisfactory learning outcomes though a lot of time might be spent.

In the current situation, learning resources are generally divided and wrapped up by education providers or courses lecturers. It considerably lacks flexibilities to fit every specific learner's time availability so that learner should get accommodated to the time length of course setting and manage to squeeze time to accomplish those learning activities. At present, as far as we know, researchers and practitioners have not investigated the learning resources adaptation in the micro learning circumstances. Our pilot work realized an adaptive mobile learning system, but it cannot go deep into in-progress courses [22], which means learners can be allocated with appropriate learning resources for an entire course, but they should prepare for themselves a detailed schedule and plan their time carefully in a comparatively long period, without personal guidance. Therefore, bringing micro learning into MOOC still exposes a huge research gap to fill.

Moreover, it is insufficient that learners only have micro learning contents adapted to their own needs by using our proposed system. This is because there would be sequences of contents suggested for them to learn in order to achieve better learning outcomes. Personalized curriculum sequencing is an important research issue for Web-based learning systems because no fixed learning paths will be appropriate for all learners [23]. Most online MOOC platforms often demand the prerequisite between course modules and/or some relationships between involved concepts to be explicitly provided by the course instructors, so that an optimizer can be ultimately used to find an optimal learning sequence of the involved concepts or modules for each individual learner after considering his/her past performances, profile, and learning styles. However, relying solely on the course instructors' input on the relationship among the involved concepts can be imprecise due to the individual biases by human experts [24]. Furthermore, the decision will become more complicated when various instructors hold conflicting views on the relationship among the involved concepts, which may hinder any plausible logical deduction [25].

\section{SYSTEM DESIGN}

How to divide the content of an entire course into small chunks is central in regard to whether learners can enjoy the micro learning experiences in fragmented pieces of time, usually less than 15 minutes. Learning contents must be adjusted to suit the limited configurations of mobile devices, such as screen size and typing methods.

In this paper, we attempt to employ both design science and quantitative research method to overcome the above challenges so as to deliver learner customized learning resources, in the form of small chunks or fine-grained units. Then learners can easily complete the learning process of each unit within fragmented pieces of time. For example, a learner may spend normally 15 minutes on his/her way home from work by train, and $\mathrm{s} /$ he prefers to use mobile devices to learn a piece of MOOC course within this time. In this case, an ideal course module delivered to him/her should be limited in the time length (e.g. 15 minutes) to ensure a micro but complete learning experience.

The framework of proposed system is shown in Figure 3.

The Learner Modelling module aims to build a specific model for each learner, on the basis of his/her historical learning behaviour. This module assesses their pre-knowledge and gathers basic information about learning styles, preference, learning purposes. These features are marked up by a set of measurable variables. It is also provided with a function, which tracks learners' behaviors during micro learning process and ensures their models being kept up-to-date once new data are detected or generated.

The Learning Resource Representation module stores all representations of the available micro learning resources. It extracts course modules from well-developed MOOC courses. Based on their time lengths, they are categorized into micro 
learning resources (less than 15 minutes) and non-micro learning resources. For non-micro learning resources, educational data mining technologies are utilized to discover which stages of them are generally finished in relatively larger time lengths, and determine time spans where pauses made by learners usually fall in. Based on the mining results, these longer course modules are cut off programmatically and encapsulated into small units with reasonable time lengths. Each unit covers the complete information of a learning section, which includes the conditions of beginning and ending, has coherent content, and can be studied individually. A metadata standard for describing micro course units is going to be established. According to this metadata, all learning resources are represented in terms of discipline, key words, time length, language of instruction, popularity, difficulty and so on [26]. Data related to good-quality and mostly-followed/discussed learner-generated content, can be refilled in to Learning Resource Repository in order to support peer-to-peer learning in MOOC[27].

A Real-Time Learner Data Retrieve module retrieves learners' real-time data, including their learning progress and time availabilities (how many minutes they prefer to use in the moment).

Furthermore, in the Learning Resource Repository Module, selected course modules are clustered using text/data mining technologies. At this stage, individual micro learning contents are able to be delivered to learners. Nevertheless, a smarter way to enable leaners to systematically utilize suggested contents is to string them in series with reasonable sequences, hence we also combine the learning path identification in our design. To realize it, this module also measures correlations among chunks, or, if feasible, derives correlations from existing MOOC course modules. It helps to set learning start point and termination point, it also distinguishes the suggested sequences of learning resources and identifies a learning path among them.
Taking data from all the above modules as input, the Adaptive Engine acts on providing learners with customized learning resources matching their current micro learning context, personal demands, learning styles and preference. It is the core of the proposed system, which embeds artificial intelligence technologies to realize the adaptive mechanism.

\section{SYSTEM EVALUATION}

In a typical working scenario of our proposed adaptive micro learning framework, the system tailors each course chunk and makes it fit to a specific time scale. Supposedly, while learners are studying MOOC course using fragmented pieces of time, they can use each time piece to go through a chunk completely, neither with any unexpected pause or breakdown, nor leaving any unfinished part to next available time. The key question of our research is to evaluate 'whether learners can enjoy MOOC courses through micro learning manner' and 'how micro learning can influence learners' knowledge acquisition'. To answer this question, we will test our system with a pilot study and formulate the following hypotheses :

- $\quad$ Participating in MOOC learning activities by accessing small unit of customized learning resource has positive impacts on learners to assimilate and internalize specific knowledge while avoiding obtaining interference information

- Learning resources in the form of visual information are easier for learners to memorize or internalize in short durations.

- Adaptive learning resources with personal tailoring help learner to conduct effective time management so as to contribute to fulfilling the requirements of entire course learning.

- Learners who do not intend to get course credits have higher satisfaction on micro learning experience than

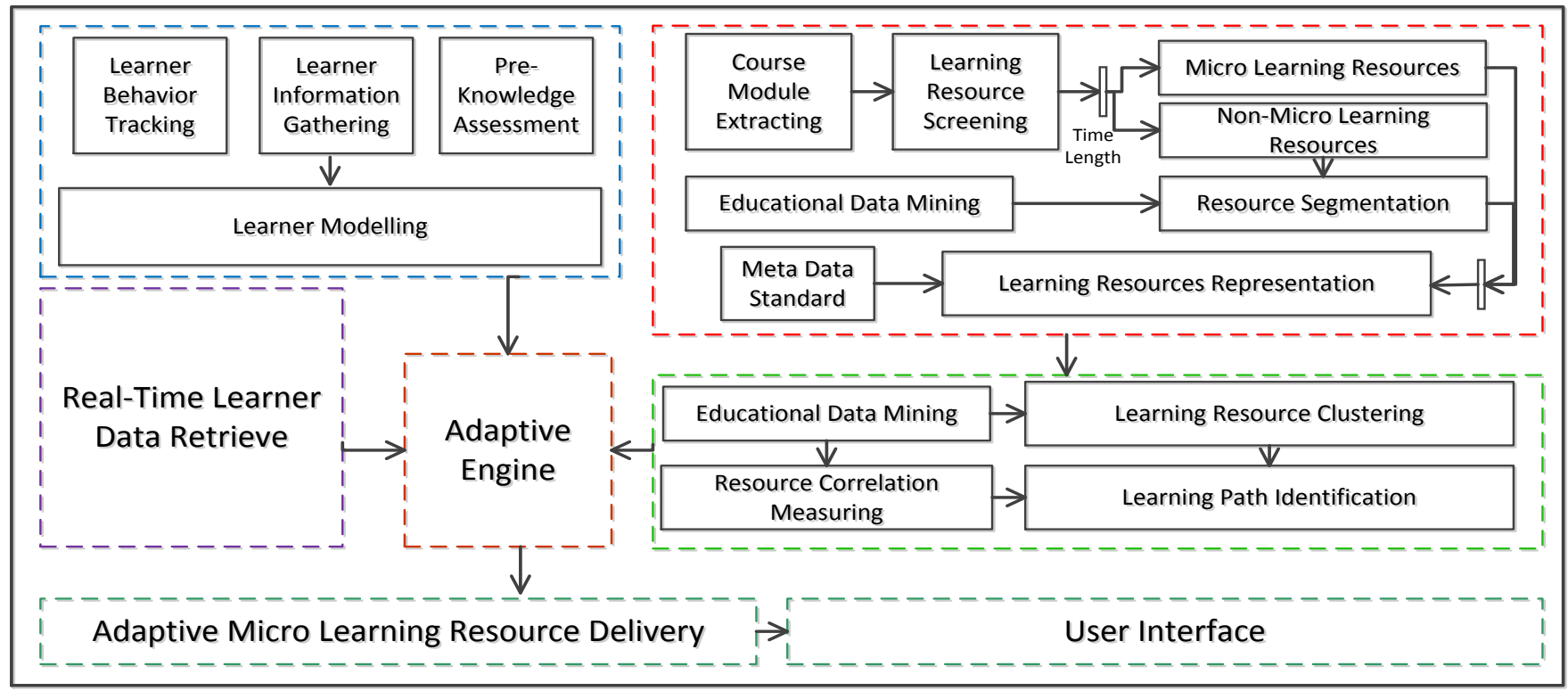

Figure 3. Framework of Adaptive Micro Learning System for MOOC 
hour-long learning.

- Micro learning contents with concrete time restrictions are better for learners to acquire targeted knowledge. Failing to complete a course unit at a time can result in information missing.

- Simple types of course assessment, such as quiz, multiple choice, etc., are suggested to be finished in micro learning units, which can timely provide refresher and knowledge review for learners, and then help to fix it in memories deeply.

We will also carry out case studies focusing on finding out how our proposed system can facilitate micro learning in MOOC and how it can, qualitatively and/or quantitatively, help learners achieve their learning expectations. We will invite MOOC learners to mark their opinions regarding the usefulness and ease of use of this system. Data from fragmented MOOC courses will also be collected to test the above hypotheses.

\section{CONCLUSION}

In this paper we introduce a proposal of enhancing current MOOC learning experiences and outcomes by introducing micro learning concept into it. Firstly we present our pilot study focusing on the development and acceptance of MOOC in Australia. Based on it, we illustrate micro learning could be a feasible way to support mastery learning and blended learning in MOOC, and list current challenges. To cover current research gaps, we propose to bring micro learning into MOOC to pursue better learning experience and outcomes. We realize our conception in a system and we describe its functions with details of each component. To empirically evaluate the functions, we point out the plan of how to carry out future case studies by formulating hypotheses of micro learning's impact on MOOC learning experience and knowledge acquisition.

\section{REFERENCES}

[1] C. King, A. Robinson and J. Vickers. 'Online Education: Targeted MOOC captivates students', Nature, vol. 505, no. 26, doi:10.1038/505026a, 2014.

[2] T. R. Liyanagunawardena, A. A. Adams and S. A. Williams, 'MOOCs: A Systematic Study of the Published Literature 2008-2012', International Review of Research in Open and Distance Learning, vol. 14, no. 3, pp. 202-227, 201.

[3] J. Baggaley, 'MOOC Rampant', Distance Education, vol. 34, no. 3 pp. 368-378, 2013.

[4] L. Pappano, 'The Year of MOOC', The New York Times, Published on November 2, 2012.

[5] I. Warrd, A. Koutropoulos, N. O. Keskin, S.C. Abajian, R. Hogue, C. O. Rodriguez and M. S. Gallagher, 'Exploring the MOOC Format as a Pedagogical Approach for m-learning', the 10th World Conference on Mobile and Contextual Learning, Beijing, China, October 2011.

[6] M. Kharbach, 'Teachers guide to the 21st century learning model : Connected learning', Educational Technology and Mobile Learning, 2012.

[7] I. Nawrot and A. Doucet, 'Building Engagement for MOOC Students', Introducing Support for Time Management on Online Learning Platforms', Proceeding of WWW'14 Companion, 2014.
[8] T. Daradoumins, R. Bassi, F. Xhafa, S. Caballe, 'A review on massive e-learning (MOOC) design, delivery and assessment', $8^{\text {th }}$ International Conference on P2P, Parallel, Grid, Cloud and Internet Computing, October 2013.

[9] Z. Chen, C. Do, R. Brandman and D. Koller, 'Self-Driven Mastery in Massive Open Online Courses', MOOCs forum, vol. 1, 2013.

[10] J. Poon, 'Blended Learning: An Institutional Approach for Enhancing Students' Learning Experiences',Journal of Online Learning and Teaching, vol.9, no.2, pp.271-289, 2013

[11] C. Milligan, A. Littlejohn and A. Margaryan, 'Patterns of Engagement in Connectivist MOOCs', Journal of Online Learning and Teaching, vol.9, no. 2, pp.149-159, 2013.

[12] X. Zhang and L. Ren, 'Design for Application of Micro Learning to Informal Training in Enterprise', $2^{\text {nd }}$ International Conference on Artificial Intelligence, Management Science and Electronic Commerce, August 2011.

[13] P.A. Bruck and M. Lindner, 'Microlearning and Capacity Building', $4^{\text {th }}$ International Micro Learning 2008 Conference, June 2008.

[14] D. Kovachev, Y. Cao, R. Klamma and M. Jarke, 'Learn-as-you-go, New Ways of Cloud Based Micro-learning for the Mobile Web', $10^{\text {th }}$ International Conference on Web-based Learning, Hongkong, December 2011.

[15] P.A.Bruck, L.Motiwalla and F. Foerster, 'Mobile Learning with Microcontent: A Framework and Evaluation', Proceeding of BLED, 2012, http://aisel.aisnet.org/bled2012/2.

[16] T. Hug and M. Lindner, 'ML: Emerging Concepts, Practices and Technologies after e-Learning', Proceedings of micro learning 2005, Austria, June 2005

[17] S. Sánchez-Alonso, M. A. Sicilia, E. García-Barriocanal, E and T. Armas, 'From Microcontents to Micro-Learning Objects-Which Semantics Are Required? (Semantics for Microlearning)', Proceedings of Microlearning Conference 2006, Austria, June 2006.

[18] A. Leene, A, 'MicroContent is Everywhere (On Microlearning)', Proceeding of Microlearning Conference 2006, Austria, June 2006.

[19] S. Liao and C. Zhu, 'Micro-Learning Based on Social Networking', $2^{\text {nd }}$ International Conference on Computer Science and Network Technology, 2012.

[20] M. I. Souza and S. F. D. Amaral, 'Educational Microcontent for Mobile Learning Virtual Environments', Creative Education, vol. 5, pp. 672-681, 2014.

[21] G. Sun and J. Shen, 'Facilitating Social Collaboration in Mobile CloudBased Learning: A Teamwork as a Service (TaaS) Approach', IEEE Transactions on Learning Technologies, vol. 7, no. 3, pp. 207-220, 2014.

[22] A. Al-Hmouz, A, J. Shen, R. Al-Hmouz and J. Yan, 'Modelling and Simulation of an Adaptive Neuro-fuzzy Inference System (ANFIS) for Mobile Learning', IEEE Transactions on Learning Technologies, vol.5, no.3, pp. 226-237, 2010.

[23] C. M. Chen, 'Intelligent Web-based Learning System with Personalized Learning Path Guidance', Computers and Education, vol. 51, no. 2, pp. 787-814, 2008.

[24] L. Wong and C. Looi, 'Adaptable Learning Pathway Generation with Ant Colony Optimization', Educational Technology and Society, vol. 12, no. 3, pp. 309-326, 2009.

[25] V. Tam, E. Y. Lam and S. T. Fung, 'Toward a Complete e-learning System Framework for Semantic Analysis, Concept Clustering and Learning Path Optimization', 12th IEEE International Conference on Advanced Learning Technologies (ICALT), pp. 592-596, Roma, Italy, July, 2012.

[26] K. Veeramachaneni, F. Dernoncourt, C. Taylor, Z. Pardos, Z. and U. O'Reilly, 'MOOCdb: Developing Data Standards for MOOC Data Science', Artificial Intelligence in Education Workshops, July 2013.

[27] Y. B. Bouyia and S. Demetriadis, 'Peer-monitoring vs. Micro-script Fading for Enhancing knowledge Aquisition When Learning in Computer-supported Argumentation Environments, Computers and Education, vol. 59, no.2, pp. 304-315, 2012. 